\title{
Intra-arrest thrombolysis in pulmonary thromboembolia with a successful clinical and neurological outcome: a case report
}

\begin{abstract}
Pulmonary thromboembolism is a highly fatal entity, and usually presents atypically. Between 80 and $90 \%$ of cases of cardiorespiratory arrest secondary to pulmonary embolism occur between 1 and 3 hours after the onset of symptoms, requiring a high degree of clinical suspicion as patient management and prognosis will depend on this. We present the case of a 72-year-old man, admitted after gastrointestinal symptoms and syncope, and who presented cardiorespiratory arrest while in the emergency room. Prior to the circulatory arrest, signs of right ventricular dysfunction and intracavitary thrombi were documented, so systemic thrombolysis was administered overall during resuscitation maneuvers. Subsequently the patient evolved successfully with no cardiac or neurological dysfunction.
\end{abstract}

Keywords: pulmonary thromboembolism, cardiorespiratory arrest, thrombolytic therapy, echocardiography
Volume I4 Issue I - 202I

\author{
Mateo Zuluaga Gómez,' Diego Fernando \\ Abreo Leal, ${ }^{2}$ Andrés Felipe Estrada \\ Atehortúa, ${ }^{2}$ Juan Pablo Muñoz Rengifo ${ }^{3}$ \\ 'Department of Emergency Medicine, Universidad CES, \\ Colombia \\ ${ }^{2}$ Department of Emergency Medicine, Pablo Tobon Uribe \\ Hospital, Colombia \\ ${ }^{3}$ Physician, fPontificia Universidad Javeriana Cali, Colombia
}

Correspondence: Mateo Zuluaga Gómez, Emergency Medicine Resident, Universidad CES. Universidad CES Emergency Medicine and Toxicology Research Line. Medellin, Colombia,Tel +5431367905 II, +54 33। 24 2I, Emailmateozg92@hotmail.com

Received: December 23, 2020 | Published: February 25, 202 |

\section{Case report}

A 72-year-old male, with no pathological or family history, presents with dizziness, abdominal pain and non-dysenteric diarrheic depositions together with a syncopal episode lasting a few minutes, presenting a full recovery without neurological deficit. 15 minutes later he enters emergency services alert, with no other symptoms, hydrated, with increased peristalsis. Parenteral hydration and initial paraclinical exams (ionogram, hemogram and electrocardiogram) are considered during his time at the emergency services, with no alterations evident. The electrocardiogram returned a sinus rhythm, no tachycardia, no signs of acute ischemia, no blockages.

As the patient improved with hydration, the decision is made to release him. After this, the patient's upper extremities begin to move rigidly, and his eyes deviate to the left side. The patient then states he feels dizzy and weak overall, he looks pale and then presents persistent hypotension, extreme bradycardia, distal coldness and desaturation. Ultrasound tracing of the subxiphoid window was performed with ultrasound imaging within the ventricles. Thrombolysis is begun using a recombinant tissue plasmogen activator $100 \mathrm{mg}$ IV over 2hours. After this is started, the patient goes into pulseless electrical activity cardiac arrest. Cerebral pulmonary reanimation maneuvers are performed. Bicarbonate (7 direct ampoules) is used, and the dose of the recombinant tissue plasmogen activator thrombolytic agent changed to $50 \mathrm{mg}$ via bolus. After 35 minutes of reanimation, the patient regains spontaneous circulation with a sinus rhythm and hemodynamic instability. Perfusion is begun with $10 \mathrm{mcg} / \mathrm{min}$ of Adrenaline and $20 \mathrm{mcg} / \mathrm{kg} / \mathrm{min}$ of Dobutamine. Assisted mechanical ventilation is continued without sedation and analgesia. $\mathrm{He}$ is transferred for an angiotomography of the pulmonary vessels where acute thrombi are identified in the main pulmonary arteries on both sides and in the segmental branches in the upper and lower lobes.

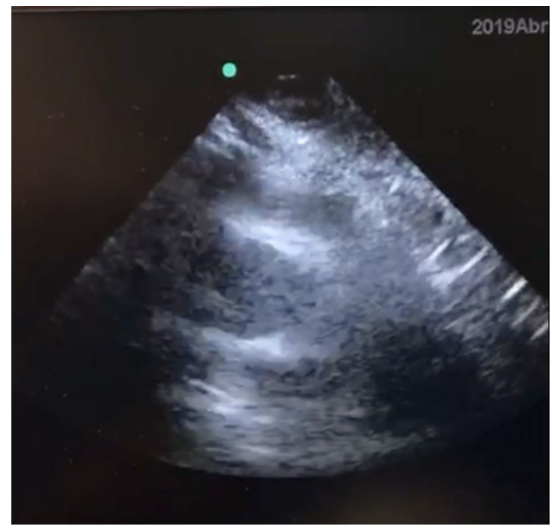

Figure IA Alterations in the size of the right ventricle, decreasing compared to the left ventricle.

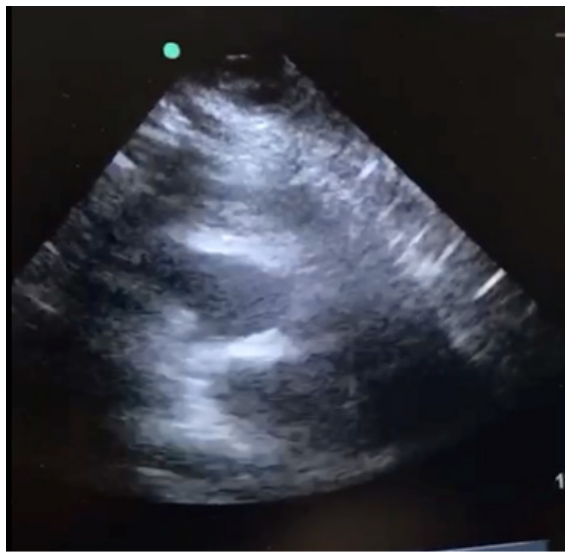

Figure IB Deviated septum. 
The patient is transferred to the Intensive Care Unit where he continues under observation for XX days. An official transthoracic echocardiogram is then performed, finding dilation of the right ventricle, a high probability of pulmonary hypertension $(49 \mathrm{mmHg})$, no systolic or diastolic disfunction of the left ventrile, with an estimated ejection fraction of $55 \%$. Tolerates extubation and removal of hemodynamic support at XX days.

Released from the hospital with oral anticoagulants after XX days with no neurological sequelae and no need for supplementary oxygen.

\section{Discussion}

Pulmonary embolism (PE) is a highly fatal condition and tends to present atypically or non-specifically, as was the case with the patient presented above. Because it compromises the pulmonary and cardiovascular systems it can have different manifestations, meaning that clinicians must employ a high degree of diagnostic suspicion when attending patient, with early recognition of red flags during care or conditions that could put the patient's life at risk in the following minutes.

The annual estimated incidence in the United States is between 1 and 2 cases per 1000 inhabitants, ${ }^{1,2}$ with $30 \%$ mortality rates when presenting as thromboembolism with signs of shock. ${ }^{1,3}$ In the case of cardiorespiratory arrest the associated mortality rate increases by up to $95 \%{ }^{4}$ There are reports in postmortem studies of unrecognized pulmonary embolism in $84 \%$ of cases $^{5}$, or, on the contrary, it is overdiagnosed in $5-25 \%$ of cases due to subsegmental pulmonary location, recent high slice CT scanners, radiology experience for the interpretation of other artefacts, among other factors. ${ }^{6}$

Between 80 and $90 \%$ of cardiorespiratory arrest cases secondary to pulmonary embolism occur 1 to 3 hours after symptoms begin. This is because thrombi are generated that can embolize pulmonary circulation giving rise to initial respiratory symptoms. ${ }^{1,7}$ The ICOPER registry included 2110 patients with confirmed PE and followed them for 3 months, describing that patients had an average age of 62 years and the main symptoms described were: dyspnea (82\%), chest pain $(49 \%)$, cough $(20 \%)$, syncope $(14 \%)$, hemoptysis $(7 \%)$, among others. ${ }^{8}$ The EMPEROR registry implemented multicentrically in emergency services amongst 1880 patients with confirmed PE, found that $3 \%$ were hypotensive upon arrival, $50 \%$ presented due to resting dyspnea, 39\% for dyspnea during exercise and $24 \%$ for signs of Deep Vein Thrombosis (DVT). ${ }^{9}$

It is estimated that pulmonary embolism is the cause of between 2 to $9 \%$ of out-of-hospital cardiac arrests (OHCA $)^{10,11}$ and of between 5 to $6 \%$ in-hospital cardiac arrests. ${ }^{12}$ However, this data is not so reliable due to the variation found in the global literature. There are other studies that report that, in $10 \%$ of cardiorespiratory arrests, a cardiac cause was considered first when the condition was in fact PE. ${ }^{13}$

Pulmonary artery occlusion, besides a different immunological and coagulation response, will give rise to increased afterload and pressure at the end of diastole in the right ventricle, decreased preload, venous return, displacement of the interventricular septum to the left and McConnell's sign, generating a state of obstructive shock or, in the worst case, cardiorespiratory arrest. ${ }^{14,15}$

Up to $30 \%$ of patients with PE present no known risk factors, ${ }^{2,16}$ as was the case with the patient reported on by the study group, confirming that a high degree of clinical suspicion must exist to arrive at a diagnosis, as well as the application of thrombolytic therapy as an emerging and lifesaving measure in the event of clinical instability or arrest, with prior knowledge of its benefits and risks.
During emergency care for this patient no CT confirmation could be performed due to rapid clinical instability, the need to secure his airways, and the early start of reanimation maneuvers. For this reason, a bedside ultrasound is performed on the patient, seeking signs of pulmonary embolism, including free intracavitary thrombi or thrombi in the pulmonary artery (as presented in this patient), or indirect signs like dilation of the Right Ventricle vs the Left Ventricle ( $>1: 1 \mathrm{RV} / \mathrm{LV})$, systolic disfunction of the right ventricle, septum displacement in the left ventricle, inferior vena cava (IVC) without collapse, or evidence of DVT in the lower extremities ${ }^{17-19}$ McConnell's sign is the most sensitive and specific indirect sign: hypokinetic free wall of the right ventricle in the four-chamber projection; with an original described sensitivity of $77 \%$ and a specificity of $94 \%$, although there are other studies that speak of a low specificity of 33 to $40 \% .^{20}$

Thrombolysis or fibrinolysis therapies are used due to the assumed benefit they provide to patients that are unstable or that require cardiopulmonary reanimation, with the theoretical assumption that they act upon coronary or pulmonary thrombosis and have an effect upon microcirculatory reperfusion (cerebral disfunction mediated by coagulation activation or endothelial interaction). ${ }^{21}$

In 1995, Jerjes-Sanchez et $\mathrm{al}^{23}$ carried out a randomized trial amongst healthy patients with a high probability of PE, applying thrombolytic therapy using $1,500,000$ UI of streptokinase and intravenous heparin anticoagulation vs. intravenous heparin alone. The study was suspended after only 4 patients with survival in favor of the group using combined therapy. ${ }^{22}$

The TICA study (A pilot randomized trial of thrombolysis in cardiac arrest), carried out in 2004, that compared 50mg of Tenecteplase to a placebo, had to be ended early for financial reasons, showing, up to that point, a significantly statistical difference in favor of the use of thrombolytic therapy. ${ }^{23}$

The literature only contains one randomized clinical study (TROICA, Thrombolysis during resuscitation for out-of-hospital cardiac arrest) that compared the use of Tenecteplase against a placebo in 1050 patients. No benefit was found in terms of return to spontaneous circulation (ROSC), 24hour survival rate, release from hospital, or 30-day survival late when compared to a placebo. ${ }^{24}$

Despite a lack of evidence, AHA (American Heart Association) and ERC (European Resuscitation Council) guidelines recommend fibrinolysis when diagnostic aids exist prior to cardiac arrest. ${ }^{25-27}$ There are other case reports using other thrombolytic agents like Streptokinase, ${ }^{28}$ Urokinase, ${ }^{29}$ and Alteplase, ${ }^{30}$ with successful outcomes in some of them.

Most studies of cardiopulmonary resuscitation in the context of pulmonary embolism are retrospective, have concluded that it is superior to standard treatment, but have many limitations (insufficient number of patients, short-term outcomes, selection bias, among others).

Alteplase is the most widely used fibrinolytic. It is applied according to the recommended dosage found in case reports, i.e., $100 \mathrm{mg}$ in IV infusion over 2 hours in unstable patients. AHA guidelines recommend its use in emergency situations (Class IIa, LOE C-LD) such as cardiorespiratory arrest due to improved reanimation outcomes compared to conventional reanimation..$^{25}$ The recommended dosage includes $50 \mathrm{mg}$ IV in bolus with the option to repeat in 15 minutes or as a single dose depending on patient weight, followed by systemic anticoagulation using unfractionated heparin. In the event thrombolysis is administered, cardiopulmonary reanimation must continue during at least 30 minutes. ${ }^{1,25,30}$ In the most recently updated 
AHA guidelines there is no evidence available to support or refute the effectiveness of empirical thrombolysis in suspected but unconfirmed pulmonary embolism.

\section{Conclusions}

Pulmonary embolism is a frequent entity that can be extremely deadly in the event it causes clinical instability or leads to cardiorespiratory arrest in patients. For this reason, a high degree of clinical suspicion should be employed to ensure timely management. In the presented patient it was shown that the return of spontaneous circulation was benefited by the application of intraarrest thrombolysis, with a good clinical (hemodynamic, cardiac, respiratory) and neurological outcome at the time of release.

\section{Acknowledgments}

None.

\section{Conflicts of interest}

The authors declare that we have no conflicts of interest. This case report was authorized by the patient and by the institution's ethical committee.

\section{Funding}

None.

\section{References}

1. Ebrahim A, Richards G. Cardiac arrest due to pulmonary embolism. Indian Heart J. 2018;70(5):731-735.

2. Heit JA, Spencer FA, White RH. The epidemiology of venous thromboembolism. J Thromb Thrombolysis. 2016;41(1):3-14.

3. Stulz P, Schläpfer R, Feer R, et al. Decision making in the surgical treatment of massive pulmonary embolism. Eur J Cardiothorac Surg. 1994;8(4):188-193.

4. Bailén MR, Cuadra JA, Aguayo De Hoyos E. Thrombolysis during cardiopulmonary resuscitation in fulminant pulmonary embolism: a review. Crit Care Med. 2001;29(11):2211-2219.

5. Karwinski B, Svendsen E. Comparison of clinical and postmortem diagnosis of pulmonary embolism. J Clin Pathol. 1989;42(2):135-139.

6. Hutchinson BD, Navin P, Marom EM, et al. Overdiagnosis of pulmonary embolism by pulmonary CT angiography. AJR Am J Roentgenol. 2015;205(2):271-277.

7. Schmid C, Zietlow S, Wagner TO, et al. Fulminant pulmonary embolism: symptoms, diagnostics, operative technique, and results. Ann Thorac Surg. 1991;52(5):1102.

8. Goldhaber SZ, Visani L, De Rosa M. Acute pulmonary embolism: clinical outcomes in the International Cooperative Pulmonary Embolism Registry (ICOPER). The Lancet. 1999;353(9162):1386-1389.

9. Pollack CV, Schreiber D, Goldhaber SZ, et al. Clinical characteristics, management, and outcomes of patients diagnosed with acute pulmonary embolism in the emergency department: initial report of EMPEROR (Multicenter Emergency Medicine Pulmonary Embolism in the Real World Registry. J Am Coll Cardiol. 2011;57:700-706.

10. Kürkciyan I, Meron G, Behringer W, et al. Accuracy and impact of presumed cause in patients with cardiac arrest. Circulation. 1998;98(8):766-771.

11. Bergum D, Nordseth T, Mjølstad OC, et al. Causes of in-hospital cardiac arrest - incidences and rate of recognition. Resuscitation. 2015;87:63-68.

12. Kürkciyan I, Meron G, Sterz F, et al. Pulmonary embolism as a cause of cardiac arrest: presentation and outcome. Arch Intern Med. 2000;160(10):1529-1535.
13. Bergum D, Nordseth T, Mjølstad OC, et al. Causes of in-hospital cardiac arrest - incidences and rate of recognition. Resuscitation. 2015;87:63-68.

14. Silfvast T. Cause of death in unsuccessful prehospital resuscitation. $J$ Intern Med. 1991;229(4):331-335.

15. Goldhaber S, Braunwald E. Pulmonary embolism. Heart Disease. 1992:1558-1580.

16. Wood KE. Major pulmonary embolism: review of a pathophysiologic approach to the golden hour of hemodynamically significant pulmonary embolism. Chest. 2002;121(3):877-905.

17. Lee $\mathrm{LH}, \mathrm{Gu} \mathrm{KQ}$, Heng D. Deep vein thrombosis is not rare in Asia? The Singapore general hospital experience. Ann Acad Med Singapore. 2002;31(6):761-764.

18. Labovitz M, Noble VE, Bierig SA. Goldstein. Focused Cardiac Ultrasound int he Emergent Seting: A Consensus Statement of the American Society of Echocardiography and the American College of Emergency Physicians. $J$ Am Soc Echocardiogr. 2010;23(12):1225-1230.

19. Borloz MP, Frohna WJ, Phillips CA, et al. Emergency department focused bedside echocardiography in massive pulmonary embolism. Journal of Emergency Medicine. 2011;41(6):658-660.

20. Esaki HC, Knight R, Noble J, et al. Detection of Acute Pulmonary Embolism by Bedside Ultrasound in a Patient Presenting in PEA Arrest: A Case Report. Case Reports in Emergency Medicine. 2012;794019.

21. Casazza F, Bongarzoni A, Capozi A, et al. Regional right ventricular dysfunction in acute pulmonary embolism and right ventricular infarction. Eur J Echocardiogr. 2005;6(1):11-14.

22. Böttiger BW, Martin E. Thrombolytic therapy during cardiopulmonary resuscitation and the role of coagulation activation after cardiac arrest. Current Opinion in Critical Care. 2001;7(3):176-183.

23. Jerjes J, Ramirez A, de Lourdes M, et al. Streptokinase and heparin versus heparin alone inmassive pulmonary embolism: a randomized controled trial. J Thromb Thrombolysis. 1995;2:9-22.

24. Fatovich DM, Dobb G, Clugston R. A pilot randomised trial of thrombolysis in cardiac arrest (the TICA trial). Resuscitation. 2004;61(3):309-313.

25. Botinger BW, Arnzt HT, Chamberlain DA, et al. Thrombolysis during resuscitation for out-of-hospital cardiac arrest. $N$ Eng $J$ Med. 2008;359:2651-2662.

26. Link MS, Berkow LC, Kudenchuk PJ, et al. Part 7: Adult Advanced Cardiovascular Life Support: 2015 American Heart Association Guidelines Update for Cardiopulmonary Resuscitation and Emergency Cardiovascular Care. Circulation. 2015 3;132(18 Suppl 2):S444-S464.

27. Bu-Laban RB, Christenson JM, Innes GD, et al. Tissue plasminogen activator in cardiac arrest with pulseless electrical activity. $N$ Engl $J$ Med. 2002;346(20):1522-1528

28. Truhlář A, Deakin CD, Cardiac arrest in special circumstances section Collaborators, et al. European Resuscitation Council Guidelines for Resuscitation 2015: Section 4. Cardiac arrest in special circumstances. Resuscitation. 2015;95:148-201.

29. Renkes-Hegendörfer U, Hermann K. Successful treatment of a case of fulminant massive pulmonary embolism with streptokinase. Anaesthesist. 1974;23(11):500-501.

30. Böttiger BW, Reim SM, Diezel G. Successful treatment of a fulminant pulmonary embolism using a high-dose bolus injection of urokinase during cardiopulmonary resuscitation. Anasthesiol Intensivmed Notfallmed Schmerzther. 1991;26(1):29-36.

31. Langdon RW, Swicegood WR, Schwartz DA. Thrombolytic therapy of massive pulmonary embolism during prolonged cardiac arrest using recombinant tissue-type plasminogen activator. Ann Emerg Med. 1989;18(6):678-680. 